\title{
What really matters at the end: perspectives from a patient, a family member and an oncologist
}

\author{
Cite as: CMAJ 2018 April 16;190:E473-5. doi: 10.1503/cmaj.171285
}

CMAJ Podcasts: article reading at https://soundcloud.com/cmajpodcasts/171285-enc

\begin{abstract}
$\mathrm{t}$ is not uncommon for physicians to write about what "they think" matters to patients. This essay explores "what really matters" from the perspective of a patient, a family member of another patient and an oncologist. The patient was a 58-year-old woman with recurrent metastatic small bowel cancer. The family member is the spouse of a 48-year-old man who had advanced gastroesophageal cancer. The medical oncologist is a midcareer clinician-scientist who cared for both patients.

The perspectives presented in this essay evolved from conversations that occurred initially between the oncologist and each of the other authors individually; eventually, the three authors met to discuss writing an essay. The three sections were written independently to ensure that they accurately reflected each author's personal perspectives.
\end{abstract}

\section{A patient's perspective}

After my diagnosis, I had to accept that I am not invincible. Once diagnosed with cancer, you will never be treated the same again. You will be perceived as fragile, weak and frail. Unless they have walked your path, others cannot know

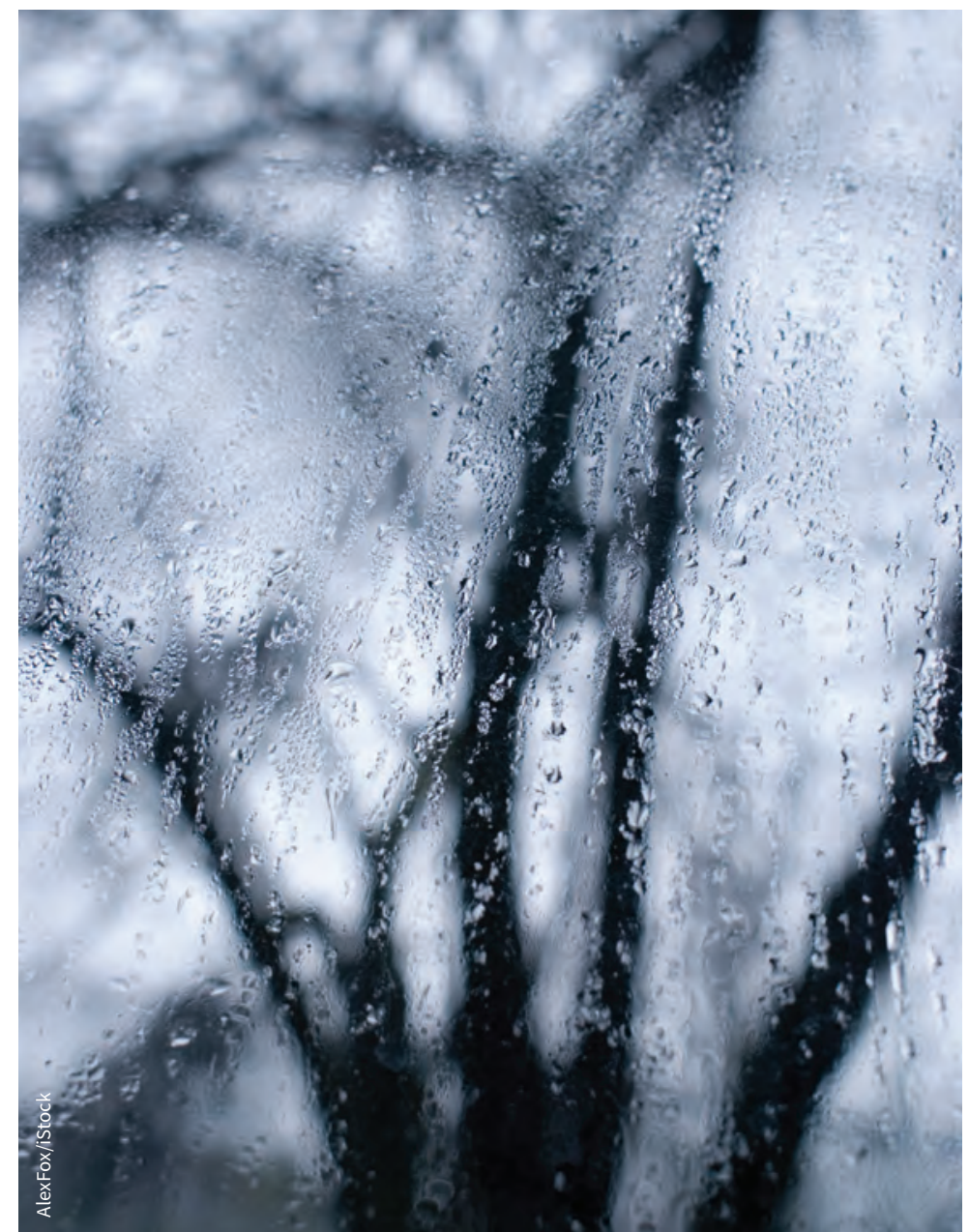

our wealth, status or privilege. Without fear of death, we can live as full a life as possible. I chose to live joyfully and not accept just to exist!

In walking my cancer trail, I have been blessed to cross paths with some amazing people. It is imperative to have a medical team that is competent, attentive, efficient and compassionate. Doctors with minimal egos. Doctors who have ears for listening. These doctors know the difficult art of listening, have the ability to stay focused and to make my concern important. Good listeners know how to make me understand their perspective and give me time to process; this makes me feel worthy and important. These doctors are very aware that waiting breeds anxiety and distrust. The diagnosis of cancer quickens time and patients lose patience; the

how tired, cold, weak, painful or anxious having cancer can be.

At this juncture, it would be well advised to accept that this is your diagnosis, your life, your death and that you must own it. The cancer trail will be less burdened by accepting the impermanence of the human condition. We are truly equals with the same conclusion no matter what good doctor will realize this. My experience has been superb, blessed with staff who never left me worried if the test has been booked, the diagnosis delayed or my symptoms untreated.

As a patient, we too have obligations to our doctors. We must give our doctors permission to be honest. Sometimes with this honesty comes words of pain, but this in 
turn facilitates an understanding so that if the patient says, "no thank you," the doctor will understand. This honesty comes not from ego or extended education; it comes from the heart. Honesty builds trust, and trust leads to better communication, better symptom management and an enriched quality of life. I have always felt like my voice is heard. I often see a flush of relief from the young doctor who realizes that I understand where this race stops, so he need not find words to mask the seriousness of the situation. I encourage these doctors to speak openly. cially if it is preceded by the word incurable. It is amazing how two words together can have such a big impact. Our epicentre comprised three people: my husband, his oncologist and myself. We were anchored together as a team within moments of his diagnosis. In this context, the process of "team-building" is full of paradox and irony. Patients and families seek out the best and most compassionate care, to build a "dream team," all within the "nightmare" of cancer. We all know where this path ends. It is just a matter of negotiating the time between the start and the finish.

\section{"I often see a flush of relief from the young doctor who realizes that II understand where this race stops, so he need not find words to mask the seriousness of the situation."}

Some of my friends were amazed that I declined chemotherapy. It was the correct decision for me; I have had three plus years and a gifted life. Treatment becomes an addiction for some patients who become terrified to stop and lose their support team. I pay close attention to "appointmentitis." My team understands that each day is precious and make every effort to stack my appointments.

Having loving friends and family, and a stable home make cancer bearable. Having physical touch reinforces that "someone still thinks I am worthy of touch." The warmth of hands relieves anxiety and offers connection. To be hugged or held reminds the patient that they are loved. I have relied on calming activities such as gardening, walking, music and working the farm. I seldom think about cancer unless I am at the clinic. I now pay close attention to and appreciate my many blessings.

\section{A family member's perspective}

I became a widow at 42 years of age. I lost my husband after a 16-month battle with metastatic gastroesophageal cancer. Cancer is a word no one ever wants to hear, espe-
As the primary caregiver, my role was to listen, interpret and organize information in a way that was digestible and honest while looking for hope. This was the most difficult task. "Making lemonade out of lemons," as my husband would say. I sought to make each day the best possible for my husband and my family; to free them from emotional pain, physical discomfort and anxiety. Most days, this was easier said than done. I discovered early on that the "system of care" was not a system at all. "System" implies connection between parts forming together as a whole. What I encountered was, for the most part, contrary to this definition. A set of binders containing all necessary health and care information became my constant companions. This enabled collaboration among parts of the system where there was none.

We did have glimmers of hope and cause for celebration. The first line of palliative chemotherapy gave us nine months within which to make happy memories. We planned activities to make the most of our time together. We pushed the boundaries for travel while doing our best to mitigate risk.
It was hard to know what to hope for. The most hopeful scenario would be to get better and never look back. Without that option available, the guiding light for me was to balance the desire for more time with quality of life. I had the good fortune of reading Being Mortal by Atul Gawande. This book in some way influenced my every decision. Our decision-making was framed within a context of humanism and compassion as we balanced "curative" versus "care-ative" approach to treatment options.

In the darkest of days, there is opportunity for learning and growth. Despite finding ourselves in a scenario we could never have imagined, our team became a cherished relationship characterized by compassion, hope, care, comfort and understanding. Perhaps that is the key to success as a caregiver, to seek out the people who and things that contribute to the best possible life in the face of death. It is all any of us could hope for under the circumstances.

\section{An oncologist's perspective}

I gravitated to oncology because of the rich doctor-patient relationships. I knew I would cherish these privileged conversations throughout my career. During my training, I was surprised by the magnitude of "benefit" associated with many standard palliative therapies. Although some treatments offer substantial benefit to patients, I was struck that many standard treatments extend life by only a number of weeks. These initial impressions were formed when I was more layperson than oncologist; years later, I still wonder to what extent patients understand how marginal some of our treatments are. Despite limited benefits of many standard regimens, I learned how oncologists can make a real difference through compassion and symptom management. Having been in practice for a decade, I now retain a healthy skepticism about how much our drug therapies actually benefit patients. In caring for the two patients described in this essay, I struggled with how to balance discussions of benefit and harms, and trying to strike a balance with hope and realism.

I worry that technology-driven medicine has led to a decline in our traditional 
"art" that emphasized caring and compassion. The quality-of-life "cost" of new therapies to a patient and the associated financial costs to society make it increasingly important to discuss these issues. However, I have learned that no two patients are alike in how they balance the pros and cons of treatment for incurable cancer. What remains uniform across all patients is the need for honest communication and compassion. For a number of reasons, including the fear of taking away hope and emotional discomfort, these conversations may not happen as often as they should.

Although I try to communicate clearly these issues to my patients, I know I could do a better job. Many tests and treatments are done because they represent "standard care," even though the extent to which they align with the values of each patient is not clear. I struggle with questions such as how to explain the absolute benefit of therapies better? How to help patients find hope in incurable cancer? At what point is "hope" helpful and at what point is "false hope" harmful? Is there intrinsic value in "doing something?" What really does matter to my patients? Although careful research might provide insight to some of these questions, the most powerful lessons will come from our patients and their families.

\section{Putting it together}

Patients and families facing incurable cancer will have unique goals, preferences and needs. What unifies us is the search for hope and meaning, when from the outset, there appears to be none. We all hope for long lives filled with joy and meaning. When that time is cut short, we must shift our hope toward care that is focused on a life that is free from as much pain, discomfort and anxiety as possible, and a death that comes as peacefully and humanely as possible.

\section{Rachel Koven MSc \\ Penny Nelson RMT (deceased) \\ Christopher M. Booth MD}

Department of Oncology, Queen's

University, Kingston, Ont.

This article has been peer reviewed.

Acknowledgements: The authors thank Gord Sinclair and Duncan Sinclair for their input on earlier drafts of this manuscript.

We lost Penny just before the submission of this article. We offer these perspectives as a tribute to the many lessons we learned from her. We hope that our combined voices will provide comfort and support to others on similar journeys. 